\title{
$5 \%$ Rule Disclosure and Stock Trading Volume : Evidence from Korea
}

\author{
Eung-Gil KIM ${ }^{1}$, Sook-Min KIM²
}

Received: September 06, 2019 Revised: September 24, $2019 \quad$ Accepted: September 25, 2019

\begin{abstract}
Despite the fact that the implementation of $5 \%$ rule is widely recognized to enhance the transparency of capital market and fairness of corporate governance market, a few evidences present information effect of 5\% rule. Using 7,088 non-financial firm-year observations listed on the Korea Stock Exchange from 2006 to 2012, we analyze the relation between trading volume and 5\% rule disclosure. The results show that the daily and abnormal trading volume is increased when 5\% rule disclosure is released. Moreover, the trading volume is significantly increased during cooling period. Specifically, trading volume is significantly greater when one day before cooling period or the expiration day of cooling period. We also find the information effect of firms with stable ownership structure before $5 \%$ rule disclosure is relatively smaller than the firms with unstable ownership structure with unstable ownership structure. These results imply that capital market participants use the information from 5\% rule disclosure and reflect in their real economic decision.
\end{abstract}

Keywords : 5\% Rule, Information Effect, Trading Volume, Ownership Structure

JEL Classification Code : M41, O16, G12, G32

\section{Introduction}

The implementation of $5 \%$ rule is widely recognized to enhance the transparency of capital market and fairness of corporate governance market. The article 147 of Korean Financial Investment Services and Capital Markets Act states $5 \%$ Rule, which requires full disclosure of stock holdings plan and purpose to report Financial Services Commission and Korea Stock Exchange if block shareholders newly purchase $5 \%$ of listed firm. $5 \%$ rule is significant because it plays an important role as warning system to investors and management by providing the material information that

1 First Author, Assistant Professor, Dept. of Accounting, Soongsil University, Korea. [Postal Address: 369 Sangdo-ro, Dongjak-gu, Seoul, 06978] Email: egilkim@ssu.ac.kr

2 Corresponding Author, Assistant Professor, Solbridge International School of Business, Woosong University, Korea. [Postal Address: 128 Uam-ro, Dong-gu, Deajeon, 34613, Korea] Email: sookminkim@gmail.com

(c) Copyright: Korean Distribution Science Association (KODISA) This is an Open Access article distributed under the terms of the Creative Commons Attribution Non-Commercial License (http://Creativecommons.org/licenses/by-nc/4.0/) which permits unrestricted noncommercial use, distribution, and reproduction in any medium, provided the original work is properly cited. contains the possibility of changing management right. Moreover, 5\% rule prevents stock accumulation that has a purpose of hostile M\&A and possibly contributes to monitor of unfair trading for regulators.

We chose Korea as our research setting because Korea has made significant improvement in 5\% rule. Korea has been implemented 5\% rule since 1976. In 2005, the rule has been enhanced to have a 'cooling period' for 5 days if block holders newly acquire 5\% shares or the purpose of 5\% share acquisition is changed from investment to management participation. In 2013, Korea tightens 5\% rule that involve administrative measures (i.e., warnings, accusation) as well as penalty surcharge if new black holders violate it. On the other hand, Kim (2015) criticize 5\% rule in Korea is not sufficient to prevent hostile M\&A and disturbing stock market. He suggests shorten reporting periods of disclosure and extending the cooling period. Korea require to disclosure 5\% rule within 5days, while Australia and England force to disclose the information within 2 days and Germany require informing immediately. Some anecdotal evidences also suggest there is a loophole under $5 \%$ rule of Korea (Kim, 2018). For example, Sovereign Asset Management who is known as one of the biggest hedge fund acquired $14.99 \%$ 
shares of SK and became the largest shareholder. They made several interventions such as the change of top executives, improvement of corporate governance, liquidation of subsidiaries. SK spent approximately 1 trillion won to protect management right. Carl Icahn who is also considered as one of famous hedge fund activists acquired $6.59 \%$ of Korean Tobacco and Ginseng in 2006. Initially, he reported the purpose of massive stock acquisition was management participation and stock price was rapidly increased for one year. However, He changed the purpose of massive stock acquisition from management participation to investment and sold all shares within one year. The capital gain of Carl Icahn was approximately 125 million dollars. Thus, we expect the 5\% rule disclosure in Korea provides an interesting research environment to investigate the information effect and corporate governance as well.

Our study is attempted to present several differences to the literature. First, this study aims to provide the information effect of unscheduled event. Most of accounting literature focuses on the existence of information effect of scheduled events (i.e., earnings news) and consistently reports the positive relationship between earnings news and trading volume (Beaver, 1968; Bamber, 1987; Ajinkya, Atiase, \& Gift, 1991; Bamber \& Cheon, 1995; Barron No Reference 2005). Our study analyzes the information effect of 5\% rule disclosure, which is unscheduled event that causes the uncertainty of newly investment and information asymmetry. Second, our research considers the periodical information effect of 5\% rule disclosure, especially cooling period. The prior studies present the overall consequences (e.g., stock return, bid-ask spread, stock turnover, tobin's q) of 5\% rule disclosure day only (Um, 2012; Cho \& Shin, 2013; Cho, 2013; Seon, 2015). This study analyzes not only the information effect of disclosure day, but also cooling and post-cooling period, because $5 \%$ disclosure brings the different level of loosening information asymmetry for each period. Last, we consider the changes of large shareholders (Kim \& Byun, 2001; Kim, 2018; Park, 2019). Park (2019) points the prior level of corporate governance leads the different market reaction of disclosure. Despite the fact that $5 \%$ rule disclosure brings the huge changes of corporate ownership structure, prior studies focus on the market liquidity or firm value of 5\% disclosure rule without considering the ownership structure. Our study attempts to suggest the periodic information effect of $5 \%$ rule, and to present the evidence whether prior governance affects the differentiate interpretation of $5 \%$ disclosure.

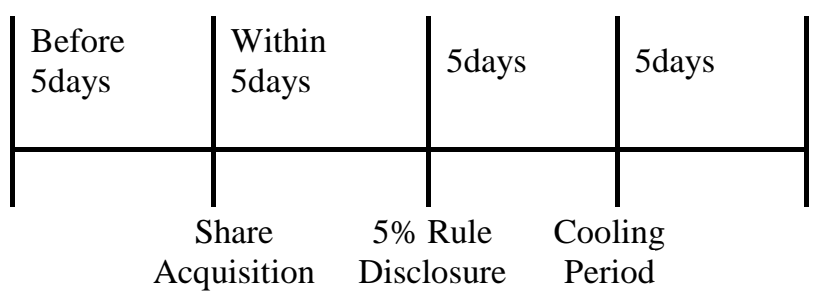

Period1 Period2 Period3 Period4

Figure1: Timeline of $5 \%$ Rule Disclosure ${ }^{3}$

This paper examines the relation between 5\% rule and trading volume. First, we focus on the information effect from the 20days before block holders share acquisition to post 20 days after the end of cooling period. The detail schedule is presented in Figure $1 .{ }^{4}$ We divide the timeline of 5\% rule disclosure to four periods, because we expect that it leads the policy implications of $5 \%$ rule. If the $5 \%$ rule disclosure contains the enough information to market participants, the second period shows the greater market reaction than the first period, the 5\% rule, thus, is effective and beneficial. Furthermore, if the cooling period is long enough to make decision by market participants, the fourth period shows the smaller market reaction than the third period. However, we cannot rule out the possibility that investor make decisions just before or after the end of cooling period. If that is the case, the policy maker should consider the extension of the cooling period suggested by Kim (2015).

Second, we analyze the information effect of $5 \%$ based on corporate governance. We use the change of large shareholders as a proxy of corporate governance (Kim \& Byun, 2001; Kim, 2018; Park 2019). If ownership structure is stable before $5 \%$ rule disclosure, the information effect is relative smaller compared to unstable firm.

We expect to provide useful insight regarding the information effect of 5\% rule disclosure. Prior studies focus pre and post stock market reaction of 5\% rule disclosure, while we consider trading volume of share acquisition, 5\% disclosure and cooling period. Especially, our results add the evidences of information effect for cooling period. Moreover, our results shed the light on the importance of corporate governance. Even if the disclosure rule is implemented to protect management and investor, stable and solid corporate governance is a precondition to deliver the material information that affects stock market participants' decision making.

\section{Literature Review and Hypotheses}

3 Source: Korean National Law Information Center (2019)

4 First period is pre-acquisition period. Second period is from share acquisition to $5 \%$ rule disclosure. Third period is from $5 \%$ rule disclosure to cooling period. During cooling period, additional share acquisition and management participation is prohibited to new block holders to protect management and investors. Last period is post-cooling period. 


\subsection{The Information Effect of $5 \%$ Rule Disclosure}

Traditionally, prior studies provide the evidences between earnings announcements which are considered as one of the representative scheduled events and stock trading volume rather than other information disclosures (Beaver, 1968; Bamber, 1987; Ajinkya et al., 1991; Bamber \& Cheon, 1995; Barron et al., 2005). For example, Beaver (1968) provide that stock return and trading volume is significantly increased after releasing earning news. In same vein, Bamber (1987) show trading volume is increased if unexpected earnings contain a number of new information. Barron et al. (2005) find the information effect of earnings news, especially investor uses the information to adjust their prior belief. Overall, this line of literature reports that trading volume is increased surrounding earnings announcement, because earning announcements play an important role of adjusting investors prior belief by providing the additional information, and reduce the information asymmetry, thus, is reduced.

Despite the fact that unscheduled events lead more severe information asymmetry and uncertainty among market participants, only few evidences report so far and that even focus on the literature of management earnings forecast (Waymire, 1984; Ajinkya \& Gift, 1984; Sohn \& Cheon, 2000; Cho \& Kwon, 2013). Sohn and Cheon (2000) documents the information effect of management earnings forecast based on the abnormal trading volume. Cho and Know (2013) adds the evidences that trading volume surrounding management forecast disclosure is significantly related to belief jumbling, a proxy for investor disagreement over management forecast information. These lines of literature provide the evidences that unscheduled events also have the information effect to capital market as well as scheduled event.

Recently, some studies documents consequences of 5\% rule disclosure (Um, 2012; Cho \& Shin, 2014; Cho, 2013; Seon, 2015). Um (2012) find that the information effect of 5\% rule based on the abnormal stock return. Cho and Shin (2014) suggests that the 5\% rule is beneficial because the adoption of $5 \%$ rule brings the market liquidity to the firms. However, Cho (2013) reports the presence of block shareholders negatively affects the firm value. In addition to Cho (2013), Seon (2015) also documents there is actual friction regarding $5 \%$ rule, and suggests that the policy makers should consider the cost of 5\% rules such as lower stock liquidity and higher transaction cost.

We argue the massive share acquisition leads both uncertainty of future business and higher information asymmetry. The massive share acquisition is considered as unscheduled event to management and investors (Um, 2012). Especially, the purpose of acquisition is ambiguous until the $5 \%$ rule disclosure. However, if 5\% rule is disclosed to the public, it is expected to reduce information asymmetry between new block holders and management/investors and uncertainty among market participants (Cho \& Shin, 2014).
As mentioned above, we divide the timeline of $5 \%$ rule disclosure to four periods. First period is pre-acquisition period. Second period is from share acquisition to $5 \%$ rule disclosure. Third period is from 5\% rule disclosure to cooling period. Last period is post-cooling period. We expect each period has a different information effect. We argue the trading volume of second period relatively increases compare to the trading volume of first period if the 5\% rule disclosure provides the useful information that are enough to alleviate the uncertainty and information asymmetry to management and investors (Um, 2012). If 5\% rule disclosure provides detail information of acquisition plan and purpose, investors reflect and use this information into their real economic decision. If belief jumping occurs after 5\% rule disclosure or the disclosure contains new information, investors adjust their expectation (Barron et al., 2005). Thus, trading volume of second period is greater than the trading volume of first period.

If management action reaches the limit to massive share acquisition, the uncertainty of stock market remains until the end of cooling period (Cho, 2013). If that is the case, there is a possibility that the trading volume of post cooling period lasts higher. Kim (2015) implies that the cooling period is too short to make decision over the new block shareholders, the cooling period, thus, should extend like U.S. ${ }^{55}$ However, during cooling period, top management grasps the purpose of massive share acquisition and prepares a way to enhance management right. If management properly takes action against new block holder during cooling period, the uncertainty of stock market is also reduced after cooling period (Cho \& Shin, 2014). In such a context, we expect the trading volume of fourth period is smaller than the trading volume of third period. Accordingly, our hypothesis 1-1 and 1-2 are suggested as follow.

Hypothesis1-1: The trading volume of second period is greater than the trading volume of first period.

Hypothesis1-2: The trading volume of fourth period is smaller than the trading volume of third period.

\subsection{Information Effect of 5\% Rule and Governance}

Despite the fact that prior studies make an effort to enhance the understanding of the relationship between changes of large shareholder and firm value, the line of literature is still controversial (Morck, Shleifer, \& Vishny, 1998; Stulz,1988). Shleifer and Vishny (1986) emphasize the positive role of large shareholders. They argue that large shareholders play an important role in corporate governance mechanism because large shareholders are capable to gather information and analyze firm value. Thus, large shareholders

\footnotetext{
5 The cooling period of U.S regarding $5 \%$ rule disclosure is 10 days (Kim, 2015).
} 
contribute to enhance the right and value of investors. However, some studies argue that some large shareholders may establish a strategic relationship with top management (Pound, 1988). In this case, large shareholders support the top management when there is massive stock acquisition.

We note the corporate governance is also one of factors that lead a differentiate interpretation of revealed information. Since 5\% disclosure may bring a huge effect on ownership structure, we use prior ownership structure, specifically the stability of ownership, as corporate governance. The evidences regarding the stability of ownership structure based on the large shareholders are emphasized in several literatures (Kim \& Byun, 2001; Kim, 2018; Park, 2019). Park (2019) points the prior level of corporate governance leads the different market reaction of disclosure. If prior ownership structure is unstable before disclosure, the information effect is sensitive. Kim (2018) suggests that firms with changing the largest shareholder (i.e., unstable ownership structure) more than two times within one accounting period are exposed to the greater firm risk. However, if prior ownership structure is stable before disclosure, the information effect is relatively smaller. Because investor perceives there is a lack of possibility to occur hostile M\&A, even if new block holders disclose 5\% for management participation purpose. Park (2019) show only the firm with poor governance is significantly associated with stock return surrounding the changing of largest shareholders. Thus, if firm with solid and healthy governance disclose the $5 \%$ rule, it leads the smaller information effect. Based on the discussion, the following hypothesis is proposed. All above previous literature are summarized in Table 1.

Hypothesis 2: The trading volume of firm with stable ownership structure is smaller than the trading volume of firm with unstable ownership structure.

Table 1: Related literature on the link between information effect of disclosure and governance

\begin{tabular}{|c|c|c|c|}
\hline Authors and year & H1 & $\mathrm{H} 2$ & Differences from this study \\
\hline Beaber (1968) & $\sqrt{ }$ & & Information effect of earnings news, scheduled events \\
\hline Ajinkya et al. (1991) & $\sqrt{1}$ & & Information effect of analyst information, scheduled event \\
\hline Barron et al. (2005) & $\sqrt{ }$ & & Information effect of earnings news, analyst private information \\
\hline Bamber et al. (1997) & $\sqrt{1}$ & & Information effect of earning news, investor disagreement \\
\hline Waymire (1984) & $\sqrt{ }$ & & Information effect of management earnings forecasts, price reaction \\
\hline Cho and Kwon (2014) & $\sqrt{1}$ & & Information effect of management earnings forecasts, investor disagreement \\
\hline Um (2012) & $\sqrt{ }$ & & Stock market abnormal return of $5 \%$ rule disclosure \\
\hline Cho and Shin (2014) & $\sqrt{ }$ & & $\begin{array}{l}\text { Stock market liquidity of } 5 \% \text { rule disclosure, bid-ask spread, number of blockholder, stock } \\
\text { turnover }\end{array}$ \\
\hline Cho (2013) & $\sqrt{ }$ & & The relationship between firm value and firm with $5 \%$ rule disclosure \\
\hline Seon (2015) & $\sqrt{ }$ & & The friction effect of $5 \%$ rule \\
\hline Shleifer and Vishny (1986) & & $\sqrt{ }$ & The positive role of large shareholders without considering the change of large shareholders \\
\hline Pound (1988) & & $\sqrt{ }$ & The negative role of large shareholders without considering the change of large shareholders \\
\hline Brickley et al. (1988) & & $\sqrt{1}$ & The negative role of large shareholders without considering the change of large shareholders \\
\hline Kim and Byun (2001) & & $\sqrt{ }$ & Stock market reaction of the disclosure of changing large shareholders \\
\hline Kim (2018) & & $\sqrt{ }$ & Firm risk of the disclosure of changing large shareholders \\
\hline Park (2019) & & $\sqrt{ }$ & $\begin{array}{l}\text { Long term stock performance of changing large shareholders considering corporate } \\
\text { governance }\end{array}$ \\
\hline
\end{tabular}

\section{Research Methodology}

\subsection{Measure of Trading Volume}

In order to examine information effect on $5 \%$ rule, we use daily trading volume and abnormal trading volume as a proxy for information effect. ${ }^{6}$ First, we use DailyVolit to

6 Prior studies suggest that measuring trading volume and stock return reflect the different information effect of disclosure (Beaver, measure the trading volume of certain date (Kim \& Lee, 2017). We use the number of shares as a denominator to

1968; Bamber, 1987; Ajinkya et al., 1991; Bamber \& Cheon, 1995; Barron et al., 2005; Sohn \& Cheon, 2000). The trading volume reflects the changes of investor expectation, whereas the stock return considers the changes of overall market expectation. Sohn and Cheon (2000) points trading volume is beneficial, if disclosed information brings the changes of investor expectation without the changes overall market expectation. 
adjust the effect of firm size. The equation (1) is presented below:

$$
\text { DailyVOL } L_{i}=\frac{\text { Trading Volume of Firm i in day } t}{\text { The number of Shares of Firm i in day } t}
$$

However, daily volume is incapable to indicate whether trading volume is abnormal or not. Thus, we measure AbVolit to capture the information effect of unscheduled event. We apply market model to measure it. Specifically, we estimate the coefficient from past period and calculate estimated trading volume by applying the coefficient. The abnormal trading volume is the difference between estimated trading volume and actual trading volume. The equation (2) and (3) are written below:

$$
\begin{aligned}
& \text { Vol }_{m t}=\frac{\text { Trading Volume of KOSPI in day } t}{\text { The number of Shares of KOSPI in day t }} \\
& A b V O L_{i t}=\text { DailyVOL } L_{i t}-\left(\widehat{\alpha_{0}}+\widehat{\alpha_{1}} V o l_{m t}\right)
\end{aligned}
$$

The period to estimate coefficient is from -110 days to 10 days. We multiply 10 for convenient interpretation.

\subsection{Measure of Ownership Structure Volatility}

We use the changes of composition of five large shareholders as a proxy of stability of ownership structure (Kim \& Byun, 2001; Kim, 2018; Park, 2019). ${ }^{7}$ Specifically, we measure the quarterly change of five large shareholders composition for past twelve quarter (Kim, 2018). We aggregate five large shareholders for twelve quarters and adjust if there is any composition change of five large shareholders. We multiply -1 for convenient interpretation. The equation (4) is presented below:

STAOWN $=-1 \times$

$\underline{\sum_{t-12}^{t-1} \text { Th composition change of five large shareholders }}$ 12

\subsection{Measure of Ownership Structure Volatility}

As mentioned in Figure 1, we divide four periods in the timeline of 5\% rule disclosure. First period is pre-acquisition period. We expect first period does not have an information effect of $5 \%$ disclosure. Second period is from share acquisition to $5 \%$ rule disclosure. Second period starts from the day of massive share acquisition and ends the day before $5 \%$ rule disclosure. Third period is from $5 \%$ rule disclosure

\footnotetext{
7 Prior research suggests the firm with the frequent changes of large shareholder show low credibility of accounting information (Kim \& Byun, 2001; Kim, 2018; Park, 2019). Specifically, Kim (2018) argues the disclosed information regarding the frequent changes of large shareholder reveals the weakness of internal control and corporate governance. Since $5 \%$ rule brings the huge effect of ownership structure, we use prior ownership structure as the proxy of corporate governance.
}

to cooling period. This period starts from the day of $5 \%$ rule disclosure and ends the last day of cooling period. Last period is post-cooling period. The period starts from the day after cooling period and ends 20 days after the end of cooling period. Our research model is written below:

$$
\begin{aligned}
& \text { Trading Volume }=\beta_{0}+\beta_{1-3} \text { Period }(2-4)+ \\
& \beta_{4} S I Z E+\beta_{5} R O A+\beta_{6} L E V+\beta_{7} M T B+\varepsilon
\end{aligned}
$$

Where,

Trading Volume $=$ DailyVol from equation (1), AbVol from equation (3)

Period2 $=1$ if from the day of massive share acquisition to the day before $5 \%$ rule disclosure, 0 otherwise

Period3 $=1$ if from the day of $5 \%$ rule disclosure to the last day of cooling period, 0 otherwise

Period $4=1$ if from the day after cooling period to 20 days after the end of cooling period, 0 otherwise

SIZE = natural log of market value

ROA = net income divided by total asset

LEV = total liabilities divided by total assets

MTB = market value to book value

We use equation (5) to examine our hypothesis 1-1, 1-2 and 2. If the value from equation (4) exceeds the median of stability of ownership structure, we consider those samples as the group of stable ownership structure. Otherwise, the rests of our samples are included in the group of unstable ownership structure. We add SIZE, ROA, LEV, MTB as the control variables (Ji, Oh, Yoon, \& An, 2019; Chea \& Ryu, 2018).

\subsection{Sample Selection}

The initial sample consists of firm-year observation in KOSPI during the period of 2006-2012. We then delete observation with financial business. We collect the data of 5\% rule disclosure from DART, which is provided by Financial Supervisory Service in Korea. NEW Kis-ValueII offers other financial data and trading volume data. We exclude (1) the data of $5 \%$ rule disclosure if the purpose of $5 \%$ disclosure is investment (2) IPO firms invested by affiliated firms (3) if massive shares are acquired by related parties or top executives (4) firms lacking financial date from NEW KIS-ValueII. This process yields a final sample 7,088 firmyear observation from 2,363 hand collected 5\% rule disclosure. 


\section{Results}

\subsection{Descriptive Statistics}

Table 1 presents descriptive statistics for the variables used in this study. The mean value of AbVOL and DailyVOL are $0.047,0.163$ respectively. In addition to the mean value of our dependent variables, the median value of AbVOL is -0.056 , suggesting that the half of our samples shows negative abnormal trading volume. Since the median value of DailyVOL is 0.043 , daily trading volume is $4.3 \%$ of the number of shares. The mean value of STAOWN is 1.067. The result suggests that the composition of 5 large shareholders is changed at least one time for each quarter. We conduct the subsample of hypothesis 2 as median value of STAOWN. If the value of STAOWN is greater than the median of STAOWN, we consider those samples as a group of stable ownership structure. If the value of STAOWN is smaller than its median, we include those samples in a group of unstable ownership structure.

Table 2: Descriptive statistics

\begin{tabular}{|c|c|c|c|c|c|c|}
\hline \multicolumn{2}{|c|}{ VARIABLES } & MEAN & $25 \%$ & MED & $75 \%$ & STD. \\
\hline \multicolumn{2}{|c|}{$A b V O L$} & 0.047 & -0.092 & -0.056 & 0.014 & 0.440 \\
\hline \multicolumn{2}{|c|}{ SIZE } & 26.344 & 25.389 & 26.186 & 27.095 & 1.484 \\
\hline \multicolumn{2}{|c|}{$L E V$} & 0.481 & 0.300 & 0.491 & 0.645 & 0.226 \\
\hline \multicolumn{2}{|c|}{ MTB } & 0.094 & -0.096 & 0.020 & 0.134 & 0.505 \\
\hline \multicolumn{2}{|c|}{ STAOWN } & -1.067 & -1.000 & -1.000 & -0.583 & 0.000 \\
\hline \multirow[t]{2}{*}{ Period2 } & $A b V O L$ & 0.072 & -0.100 & -0.055 & 0.008 & 0.547 \\
\hline & DailyVOL & 0.191 & 0.018 & 0.043 & 0.114 & 0.549 \\
\hline \multirow[t]{2}{*}{ Period3 } & $A b V O L$ & 0.080 & -0.088 & -0.053 & 0.037 & 0.461 \\
\hline & DailyVOL & 0.195 & 0.018 & 0.046 & 0.149 & 0.466 \\
\hline \multirow[t]{2}{*}{ Period4 } & $A b V O L$ & 0.017 & -0.088 & -0.054 & 0.018 & 0.265 \\
\hline & DailyVOL & 0.132 & 0.017 & 0.046 & 0.129 & 0.268 \\
\hline
\end{tabular}

The mean of daily trading volume for Period1 (pre massive stock acquisition) and Period4 (post cooling period) are smaller than the mean of daily trading volume for Period 2 (post massive stock acquisition) and Period 3(5\% rule disclosure and cooling period). Specifically, the mean value of AbVOL and DailyVOL for Period 1 are $0.046 \%$, $1.63 \%$ and the mean value of AbVOL and DailyVOL for Period 4 are $0.17 \%, 1.23 \%$ respectively. On the other hand, the average of AbVOL and DailyVOL for Period 2 are $0.72 \%, 1.91 \%$ for Period 2 and the average of AbVOL and DailyVOL for Period3 is $0.8 \%, 1.95 \%$ respectively. Overall, the results suggest that the information effect is focused on the $5 \%$ rule disclosure and cooling period.

\subsection{T-test of Hypothesis 1 and 2}

Table 2 presents the t-test results of abnormal trading volume and daily trading volume around $5 \%$ rule disclosure. Day0 is the disclosure day of $5 \%$ rule and day +5 is the end day of cooling period. Compare to pre disclosing period, the results suggest that the mean value of abnormal trading volume of day0 show 0.168 , while the abnormal trading volume of day1 rapidly decreases from 0.168 to 0.097 . During cooling period, the mean values of abnormal trading volume significantly decrease from 0.051 to 0.033 . The mean values of abnormal trading volume gradually increase for the last day of cooling period and the first day of post cooling period. The mean value of daily trading volume also has a similar pattern. The day 0 shows the mean value of daily trading volume significantly increases from 0.241 to 0.283 and then gradually decreases during cooling period. Similarly, the mean values of daily trading volume increases from day5 to day6.

Table 3: T-test of Abnormal Trading Volume and Daily Trading Volume around 5\% Rule Disclosure

\begin{tabular}{|c|c|c|c|c|}
\hline VARIABLES & \multicolumn{2}{|c|}{ AbVOL } & \multicolumn{2}{c|}{ DailyVOL } \\
\hline DAY & MEAN & T-STAT & MEAN & T-STAT \\
\hline-4 & 0.043 & 1.33 & 0.156 & 4.80 \\
\hline-3 & 0.111 & 2.15 & 0.226 & 4.35 \\
\hline-2 & 0.142 & 2.50 & 0.259 & 4.50 \\
\hline-1 & 0.122 & 2.43 & 0.241 & 4.74 \\
\hline 0 & 0.168 & 3.57 & 0.283 & 5.95 \\
\hline 1 & 0.097 & 3.31 & 0.210 & 7.09 \\
\hline 2 & 0.051 & 2.33 & 0.166 & 7.52 \\
\hline 3 & 0.062 & 2.45 & 0.177 & 6.92 \\
\hline 4 & 0.033 & 1.61 & 0.148 & 6.99 \\
\hline
\end{tabular}




\begin{tabular}{|c|l|l|l|l|}
\hline 5 & 0.076 & 2.53 & 0.188 & 6.23 \\
\hline 6 & 0.092 & 3.07 & 0.205 & 6.78 \\
\hline 7 & 0.050 & 2.65 & 0.166 & 8.58 \\
\hline 8 & 0.034 & 2.06 & 0.148 & 8.82 \\
\hline 9 & 0.033 & 2.17 & 0.148 & 9.62 \\
\hline 10 & 0.033 & 2.17 & 0.144 & 9.62 \\
\hline 11 & 0.038 & 2.10 & 0.174 & 8.29 \\
\hline 12 & 0.055 & 2.70 & 0.151 & 8.15 \\
\hline 13 & 0.034 & 1.75 & 0.142 & 9.81 \\
\hline 14 & 0.027 & 1.77 & 0.132 & 9.15 \\
\hline 15 & 0.018 & 1.32 & & 9.40 \\
\hline
\end{tabular}

Despite the fact that there is a possibility that information leakage before disclosure 5\% rule may occurs because of large shareholders and management with information advantage, the information effect of $5 \%$ rule clearly exists. We find the information effect lasts until the first day of post cooling period, while prior study reports stock market reaction is insignificant for the post cooling period (Kim, 2008). The results imply that investors reflect the contents and purpose of $5 \%$ rule disclosure in their investment decision during cooling period. However, there is possibility that information asymmetry still remains after cooling period because our results show the abnormal and daily trading volume of day 6 is significant. We interpret this information asymmetry arises from the reaction of management. Even if the 5\% rule disclosure contains sufficient information to resolve uncertainty, the management action toward the new block holder is a major cause of stock market uncertainty. We discuss further in section 4.3.

Table 4: Subsample T-test of Abnormal Trading Volume and Daily Trading Volume around $5 \%$ Rule Disclosure

\begin{tabular}{|c|c|c|c|c|c|c|c|c|}
\hline \multirow{3}{*}{$\begin{array}{c}\text { VARIABLES } \\
\text { DAY }\end{array}$} & \multicolumn{4}{|c|}{ UNSTABLE } & \multicolumn{4}{|c|}{ STABLE } \\
\hline & \multicolumn{2}{|c|}{ AbVOL } & \multicolumn{2}{|c|}{ DailyVOL } & \multicolumn{2}{|c|}{ AbVOL } & \multicolumn{2}{|c|}{ DailyVOL } \\
\hline & MEAN & T-STAT & MEAN & T-STAT & MEAN & T-STAT & MEAN & T-STAT \\
\hline-4 & 0.043 & 1.00 & 0.155 & 3.63 & 0.044 & 0.87 & 0.155 & 3.12 \\
\hline-3 & 0.102 & 1.44 & 0.213 & 3.06 & 0.123 & 1.63 & 0.234 & 3.10 \\
\hline-2 & 0.171 & 2.19 & 0.292 & 3.66 & 0.105 & 1.27 & 0.218 & 2.61 \\
\hline-1 & 0.146 & 2.12 & 0.272 & 3.89 & 0.093 & 1.25 & 0.202 & 2.73 \\
\hline 0 & 0.200 & 2.82 & 0.313 & 4.43 & 0.124 & 2.29 & 0.232 & 4.31 \\
\hline 1 & 0.085 & 2.26 & 0.195 & 5.93 & 0.113 & 2.10 & 0.220 & 4.19 \\
\hline 2 & 0.057 & 1.88 & 0.172 & 5.61 & 0.041 & 1.37 & 0.150 & 5.07 \\
\hline 3 & 0.033 & 1.47 & 0.145 & 6.42 & 0.098 & 1.99 & 0.211 & 4.27 \\
\hline 4 & 0.027 & 0.89 & 0.146 & 4.65 & 0.042 & 1.53 & 0.158 & 5.52 \\
\hline 5 & 0.051 & 1.94 & 0.160 & 6.15 & 0.109 & 1.79 & 0.224 & 3.60 \\
\hline 6 & 0.052 & 2.13 & 0.160 & 6.80 & 0.145 & 2.36 & 0.250 & 4.14 \\
\hline 7 & 0.029 & 1.31 & 0.141 & 6.45 & 0.077 & 2.37 & 0.184 & 5.75 \\
\hline 8 & 0.013 & 0.77 & 0.124 & 7.59 & 0.061 & 1.98 & 0.175 & 5.50 \\
\hline 9 & 0.017 & 1.04 & 0.137 & 7.74 & 0.051 & 1.95 & 0.163 & 6.15 \\
\hline 10 & 0.006 & 0.37 & 0.128 & 7.05 & 0.081 & 2.26 & 0.198 & 5.46 \\
\hline 11 & 0.028 & 1.08 & 0.142 & 5.42 & 0.090 & 2.74 & 0.205 & 6.13 \\
\hline 12 & 0.009 & 0.44 & 0.126 & 5.98 & 0.063 & 1.84 & 0.182 & 5.33 \\
\hline 13 & 0.003 & 0.21 & 0.119 & 6.62 & 0.056 & 2.11 & 0.171 & 6.45 \\
\hline 14 & 0.015 & 0.78 & 0.122 & 6.22 & 0.022 & 1.15 & 0.137 & 7.35 \\
\hline 15 & -0.004 & -0.26 & 0.115 & 6.87 & 0.029 & 1.11 & 0.146 & 5.56 \\
\hline
\end{tabular}

\subsection{Regressions Analysis of Hypothesis 1}

Table 4 presents the results of hypothesis 1-1 and 1-2, the information effect of 5\% rule disclosure. Followings are noteworthy: First, we analyze the information effect of 5\% rule disclosure by using total sample. We find Period 2 which is from massive share acquisitions to pre disclose is positively related to AbVOL and DailyVOL. The results suggest that investor recompose their portfolio by going through an unscheduled event. Moreover, the result indicates that Period3 is also positively related to both AbVOL and DailyVOL. The finding implies the interpretation and analysis of $5 \%$ rule information causes stock market movement. However, Period4 is negatively associated with AbVOL and DailyVOL. We interpret the information asymmetry is reduced because of cooling period. Overall, our results suggest $5 \%$ disclosure rule provide the detailed information to market and top management and investors prepare and react for possible consequences of massive stock acquisition. We present further information in a column 2-4.

Second, we compare information effect of Period1 and Period2. We find Period2 is positively associated with both AbVOL and DailyVOL. The result indicates the trading 
volume is significantly changed when new block holders purchase massive shares.

Third, we compare information effect of Period 2 and Period3. We find Period3 is statistically insignificant. In other words, the trading volume of Period3 is indifferent with the trading volume of Period2. We interpret this result as two ways. First possibility is overreaction of stock market. Since the lack of information has left investors confused about unscheduled event, investors may make a decision to avoid uncertainty when new block holder acquire massive shares. When information is disclosed, investor may make a decision based on their interpretation and expectation. Thus, the trading volume of Period3 is offset by the trading volume of Period2. Second possibility is information leakage. If large shareholder has information advantage over investor, they may make an investment decision before disclosing $5 \%$ rule by new block holder. Investor may later make a decision when $5 \%$ rule is disclosure, because they are limited to access the purpose and contents of massive share acquisition. Thus, it may lead indifference between the trading volume of Period 3 and the trading volume of Period2. To address alternative interpretation, we analyze the information effect of $5 \%$ rule based on compliance or violate $5 \%$ rule in section 4.5 .

Lastly, we compare information effect of Period3 and Period4. We find Period4 is negatively associated with both AbVOL and DailyVOL. The results indicate that management and investor adjust their investment decision during cooling period. Furthermore, investor makes a decision shortly before the end of cooling period considering the previous results from Table 2 and Table 3 .

Table 5: Analysis on the Effect of 5\% Rule on Trading Volume

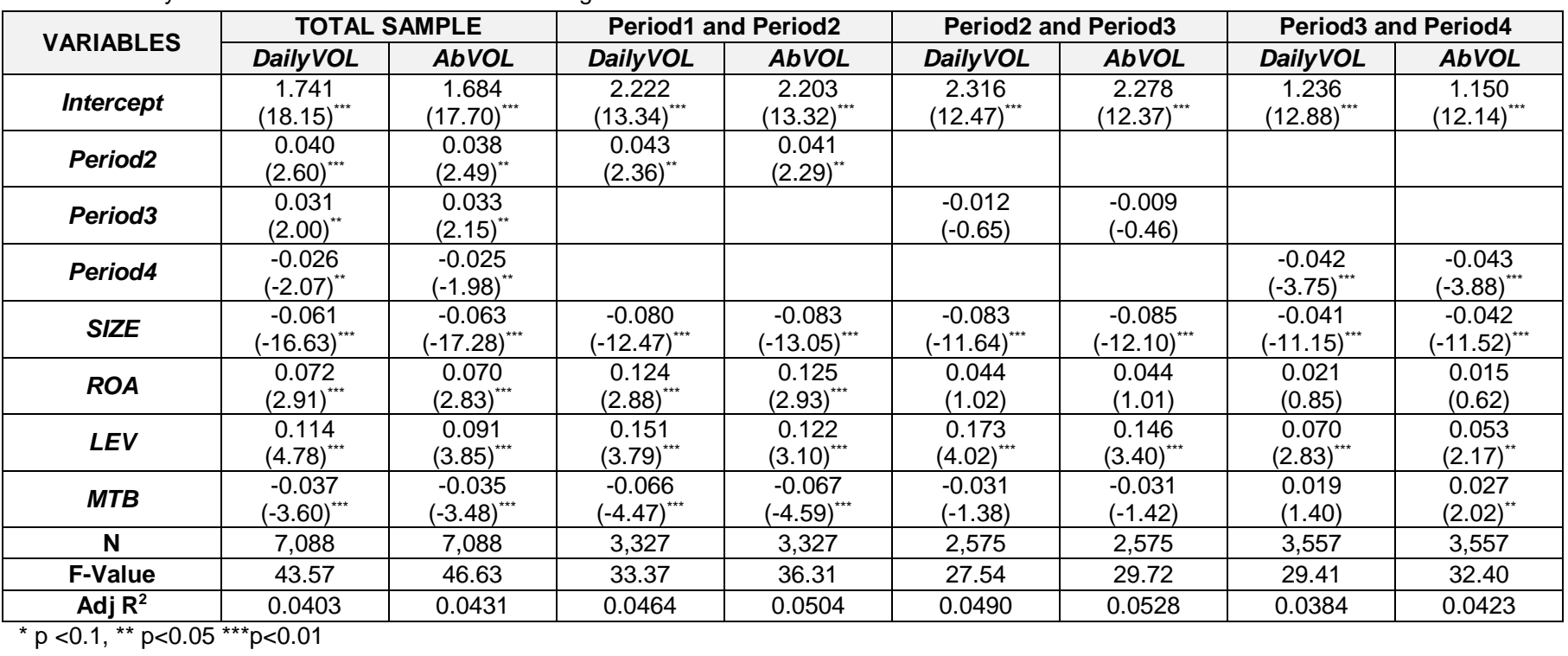

\subsection{Regressions Analysis of Hypothesis}

Table 5 presents the results of hypothesis 2, the information effect of $5 \%$ rule disclosure based on the stability of ownership structure. The first column of Table 5 is a group of unstable ownership structure and the second column of Table 5 is a group of stable ownership structure. Compare 2nd and 4th column, the information effect of 5\% rule is significant for a group of stable ownership structure, while the relation between Period 3 and trading volume is positive but insignificant for a group of unstable ownership structure. However, sample with unstable ownership structure shows statistically significant in pre and post period of disclosure. We find a positive relation between Period2 and trading volume and a negative relation between Period4 and trading volume for a group of unstable ownership structure. Corresponding with TABLE 3, investor perceives that managerial action against uncertain massive stock acquisition is well prepared, if prior ownership structure is more stable. Thus, stock market movement is relatively weak compared to a group of unstable ownership structure.

Table 6: Subsample Analysis on the Effect of 5\% Rule on Trading Volume

\begin{tabular}{|c|c|c|c|c|}
\hline \multirow{2}{*}{ VARIABLES } & \multicolumn{2}{|c|}{ UNSTABLE } & \multicolumn{2}{c|}{ STABLE } \\
\cline { 2 - 5 } & DailyVOL & AbVOL & DailyVOL & AbVOL \\
\hline \multirow{2}{*}{ Intercept } & 1.612 & 1.529 & 1.786 & 1.793 \\
& $(13.41)^{*+*}$ & $(12.88)^{*+*}$ & $(10.69)^{*+*}$ & $(10.78)^{*+*}$ \\
\hline \multirow{2}{*}{ Period2 } & 0.088 & 0.089 & 0.022 & 0.018 \\
$(0.98)$ & $(0.80)$ \\
\hline
\end{tabular}




\begin{tabular}{|c|c|c|c|c|}
\hline Period3 & $\begin{array}{l}0.019 \\
(1.04)\end{array}$ & $\begin{array}{l}0.022 \\
(1.26)\end{array}$ & $\begin{array}{c}0.047 \\
(1.83)^{*}\end{array}$ & $\begin{array}{c}0.046 \\
(1.82)^{*}\end{array}$ \\
\hline SIZE & $\begin{array}{c}-0.057 \\
(-12.22)^{*+*}\end{array}$ & $\begin{array}{c}-0.058 \\
(-12.60)^{* * *}\end{array}$ & $\begin{array}{c}-0.062 \\
(-9.78)^{*+*}\end{array}$ & $\begin{array}{c}-0.066 \\
(-10.45)^{* * *}\end{array}$ \\
\hline$R O A$ & $\begin{array}{l}-0.116 \\
(-1.37)\end{array}$ & $\begin{array}{l}-0.097 \\
(-1.16)\end{array}$ & $\begin{array}{c}0.101 \\
(3.61)^{* * *}\end{array}$ & $\begin{array}{c}0.099 \\
(3.57)^{* * *}\end{array}$ \\
\hline LEV & $\begin{array}{c}0.151 \\
(4.82)^{*+*}\end{array}$ & $\begin{array}{c}0.133 \\
(4.30)^{*+*}\end{array}$ & $\begin{array}{l}0.045 \\
(1.21)\end{array}$ & $\begin{array}{l}0.016 \\
(0.43)\end{array}$ \\
\hline $\mathbf{N}$ & 3,936 & 3,936 & 3,152 & 3,152 \\
\hline F-Value & 33.49 & 34.66 & 17.51 & 21.44 \\
\hline Adj $R^{2}$ & 0.0546 & 0.0565 & 0.0354 & 0.0419 \\
\hline
\end{tabular}

${ }^{\star} p<0.1,{ }^{\star *} p<0.05^{* * *} p<0.01$

\subsection{Additional Analysis}

Table 6 presents a robustness test, the information effect of $5 \%$ rule disclosure whether new block holders follow the disclosure rule or not. We find the trading volume of Period3 is indifferent with the trading volume of Period2 in Table 4. As mentioned above, we interpret the results may have two possible explanations either overreaction of market or information advantage. If indifference is caused by market overreaction, $5 \%$ rule disclosure may have information effect. Because it loosens uncertainty due to massive share acquisition. On the other hand, if large shareholders have information advantage of unscheduled events, they may make an investment decision prior to disclose 5\% rule. In such a case, information effect of Period 3 will be diluted because of information leakage.

As mentioned above, new block holders have an obligation to report the detail and purpose of massive share acquisition within 5days. We divide our sample to two categories. If new block holder discloses $5 \%$ rule within 5days, sample is considered as a group of compliance. If new block holder delay to disclosure the information of $5 \%$ rule, we regard sample as a group of violation. If delayed disclosure shows significant information effect, we expect the relation between Period3 and trading volume is significantly positive. However, if large shareholders have an information advantage, the information effect of Period3 is diluted due to information leakage.

According to Table 6, we find information effect of 5\% rule is significant in Period2, while the relation between Period 3 and trading volume is positive but insignificant for a violation group. On the other hand, information effect of Period 2 and 3 is significantly positive and effect of Period 4 is significantly negative for a compliance group. The results imply that large shareholders make an investment decision prior to disclose 5\% rule. Thus, information effect of Period3 is diluted because of information leakage.

Table 7: Subsample Analysis on the Effect of $5 \%$ Rule on Trading Volume

\begin{tabular}{|c|c|c|c|c|}
\hline \multirow{2}{*}{ VARIABLES } & \multicolumn{2}{|c|}{ COMPLIANCE } & \multicolumn{2}{|c|}{ VIOLATION } \\
\hline & DailyVOL & $A b V O L$ & DailyVOL & $A b V O L$ \\
\hline Period3 & $\begin{array}{c}0.035 \\
(1.85)^{*}\end{array}$ & $\begin{array}{c}0.036 \\
(1.91)^{*}\end{array}$ & $\begin{array}{l}0.023 \\
(0.92)\end{array}$ & $\begin{array}{l}0.028 \\
(1.09)\end{array}$ \\
\hline Period4 & $\begin{array}{c}-0.033 \\
(-2.05)^{* *}\end{array}$ & $\begin{array}{l}-0.033 \\
(-2.11)^{* *}\end{array}$ & $\begin{array}{l}-0.016 \\
(-0.79)\end{array}$ & $\begin{array}{l}-0.012 \\
(-0.60)\end{array}$ \\
\hline$R O A$ & $\begin{array}{l}0.131 \\
(1.40)\end{array}$ & $\begin{array}{l}0.129 \\
(1.40)\end{array}$ & $\begin{array}{c}0.074 \\
(2.80)^{* *}\end{array}$ & $\begin{array}{c}0.074 \\
(2.80)^{* *}\end{array}$ \\
\hline LEV & $\begin{array}{c}0.128 \\
(3.83)^{*+* *}\end{array}$ & $\begin{array}{c}0.110 \\
(3.33)^{*+*+}\end{array}$ & $\begin{array}{c}0.112 \\
(3.24)^{* * *}\end{array}$ & $\begin{array}{c}0.088 \\
(2.57)^{* *}\end{array}$ \\
\hline MTB & $\begin{array}{l}-0.020 \\
(-1.47)\end{array}$ & $\begin{array}{l}-0.018 \\
(-1.30)\end{array}$ & $\begin{array}{c}-0.052 \\
(-3.51)^{\star \star \star}\end{array}$ & $\begin{array}{c}-0.051 \\
(-3.46)^{* \star *}\end{array}$ \\
\hline
\end{tabular}

${ }^{\star} p<0.1,{ }^{\star *} p<0.05^{\star * *} p<0.01$ 


\section{Discussion and Conclusions}

Despite the fact that the implementation of $5 \%$ rule is widely recognized to enhance the transparency of capital market and fairness of corporate governance market, a few evidences presents the consequences of 5\% rule (Um, 2012; Cho \& Shin, 2014; Cho, 2013; Seon, 2015). In such a context, we divide four periods in the timeline of $5 \%$ rule disclosure and consider the periodical information effect using trading volume. Further, we examine the information effect of $5 \%$ rule based on the stability of ownership structure which is a proxy as corporate governance.

Using 7,088 non-financial firm-year observations listed on the Korea Stock Exchange from 2006 to 2012, we analyze the information effect of $5 \%$ rule disclosure. We present the several main findings. First, our results under ttest of our hypothesis 1-1 and 1-2 suggest that the information effect of $5 \%$ rule disclosure clearly exists. The results under t-test of our hypothesis 2 show unstable group is up to ten times higher mean value of abnormal trading volume than unstable group during Period3.

Second, the results show that the daily and abnormal trading volume is increased when $5 \%$ rule disclosure is released compared to the pre-disclosure period. Third, the trading volume is significantly increased during cooling period. Specifically, trading volume is significantly greater when one day before or the day of cooling period is ended. Fourth, we find the information effect of firms with stable ownership structure before $5 \%$ rule disclosure is relatively smaller than the firms with unstable ownership structure with unstable ownership structure. Last, to check robustness of our results, we divide samples between delayed disclosure and legitimate disclosure. If block holders violate the $5 \%$ rule and delay disclosure, the trading volume is weakly increased in a period of $5 \%$ rule disclosure and insignificant in a cooling period.

Contributions of the paper are as follows. First, we consider the periodic information effect of $5 \%$ rule disclosure, while prior research focuses on the consequence of $5 \%$ rule to suggest the cost or benefit of $5 \%$ rule (Um, 2012; Cho \& Shin, 2014; Cho, 2013; Seon, 2015). According to our results, 5\% rule has a significant information effect to reduce information asymmetry and uncertainty among market participants. Second, despite the usefulness of $5 \%$ rule disclosure, the findings suggest it is still necessary to improve the $5 \%$ rule. Based on our results, the abnormal trading volume for post cooling period is still significant, even though it is smaller than cooling period. Kim (2015) points the length of cooling period is not enough to resolve uncertainty caused by massive share acquisition. Thus, policy maker should consider the extension of the length of cooling period such as U.S. Third, the robustness check implies that large shareholders with information advantage may take advantage of investor without information of 5\% rule and realize capital gain in advance. regulators should consider shorten reporting periods of disclosure as well as a heavy penalty like German. Lastly, our results imply that stable and effective corporate governance is a precondition to deliver the material information that affects the real economic decision by investors.

Simultaneously, we acknowledge that our dataset is not sufficient to capture the disclosure quality of $5 \%$ rule. Furthermore, we cannot rule out the possibility that the results may be inconsistent with those in markets besides Korea because the detailed specification of $5 \%$ rule differs across countries and investors outside of Korea are likely to react differently, even for the same firm.

We suggest several approaches for future research into the information effect of $5 \%$ rule. Researchers are able to examine the disclosing effect of $5 \%$ rule on firm value, such as cost of equity capital to provide the usefulness of $5 \%$ rule. Likewise, we can investigate whether the $5 \%$ rule disclosure is one of the determinants of stock price crash risk. In addition, future empirical research, the investigation of the contents or disclosure quality of $5 \%$ rule would also be interesting.

\section{References}

Ajinkya, B. B., \& Gift, M J. (1984). Corporate managers' earnings forecasts and symmetrical adjustments of market expectations. Journal of Accounting Research, 22(2), 428-444.

Ajinkya, B. B., Atiase, R. K., \& Gift, M. J. (1991). Volume of trading and the dispersion in financial analysts' earnings forecasts. The Accounting Review, 66(2), 389401.

Bamber, L. S. (1987). Unexpected earnings, firm size, and trading volume around quarterly earnings announcements. The Accounting Review, 62(3), 510-532.

Bamber, L. S., \& Cheon, Y. S. (1995). Differential price and volume reactions to accounting earnings announcements. The Accounting Review, 70(3), 417-441.

Bamber, L. S., Barron. O. E., \& Stober, T. L. (1997). Trading volume and different aspects of disagreement coincident with earnings announcements. The Accounting Review, 72(4), 575-597.

Beaver, W. H. (1968). The information content of annual earnings announcements. Journal of Accounting Research, 6(1), 67-92.

Bricklet, J. A., Lease, R. C., \& Smith, C. W. (1988). Ownership structure and voting on antitakeover amendments. Journal of Financial Economics, 20(1), 267-291.

Chae, S. J., \& Ryu, H. Y. (2018). The Relationship between corporate social responsibilities and financial reporting quality: Focusing on distribution \& service companies. Journal of Distribution Science, 16(10), 77-82. 
Cho, K. S. (2013). Block ownership and firm value: KOSPI200 firms. Korean Journal of Business Administration, 26(12), 3051-3073.

Cho, M. J., \& Kwon, S. Y. (2013). Trading volume and investor disagreement around management forecast disclosures. Journal of Accounting, Auditing \& Finance, 29(1), 3-30.

Ji, S. H., Oh, H. M., Yoon, K. C., \& An, S. B. (2019). A study on earnings management in companies achieving sustainability: Accruals-based and real earnings management. Journal of Distribution Science, 17(9), 103-115.

Kim, B. T. (2015). The current states and implications of 5\% Rule (pp.1-52). Seoul, Korea: Korea Economic Research Institute.

Kim, H. R. (2018). The effect of the type of largest shareholder change on firm risk. Korean Business Education, 32(1), 71-98.

Kim, H. S., \& Cho, K. S. (2014). The effects of blockholder concentration on stock market liquidity by panel regression analysis. Korean Finance \& Knowledge, 12(2), 117-139.

Kim, S. H. (2018). Two faces of foreign capital: Gather profits and threaten management rights. Jungangsisa Magazine, Retrieved June 11, 2018, from http://jmagazine.joins.com/economist/view/321561.

Kim, S. J., \& Byun, H. J. (2001). Changes in large shareholders and performance of restructuring firms. Korean Journal of Financial Studies, 28(1), 115-148.

Kim, S. S., \& Lee, J. H. (2017). Testing the liquidity hypothesis in the Korean retail firms. Journal of Distribution Science, 15(5), 29-38.
Korean National Law Information Center (2019). Korean Financial Investment Services and Capital Markets Act (The article 147) Retrieved August 31, 2019, from http://www.law.go.kr/lsInfoP.do?lsiSeq=181870\&efYd= 20190916\#0000.

Morck, R., Shleifer, A., \& Vishny, R. W. (1988). Management ownership and market valuation: An empirical analysis. Journal of Financial Economics, 20(1), 1998, 293-315.

Seon, J. H. (2015). Friction effects of block ownership. Korean Journal of Financial Studies, 44(4), 807-827.

Shleifer, A., \& Vishny, R. W. (1986). Large shareholders and corporate control. Journal of Political Economy, 94(3), 461-488.

Stulz, R. (1988). Managerial control of voting rights. Journal of Financial Economics, 20(1), 25-59.

Sohn, S. K., \& Cheon, Y. S. (Year). A study on trading volume around management earnings forecast disclosure. Korean Accounting Review, 25(4), 27-54.

Park, Y. K. (2019). Corporate governance, largest shareholder change and stock performance. Korean Finance \& Knowledge, 17(1), 87-107.

Pound, J. (1988). Proxy contests and the efficiency of shareholder oversight. Journal of Financial Economics, 20(1), 237-265.

Um, Y. S. (2012). The role of large investors in corporate control: The analysis of $5 \%$ rule. Korean Journal of Business Administration, 25(9), 3533-3551.

Waymire, G. (1984). Additional evidence on the information content of management earnings forecasts. Journal of Accounting Research, 22(2), 703-718. 